\title{
Thermal Degradation of Polyacrylonitrile, Polybutadiene, and Copolymers of Butadiene With Acrylonitrile and Styrene
}

\begin{abstract}
Sidney Straus and Samuel L. Madorsky
Polybutadiene and a copolymer consisting of 76.5 percent butadiene and 23.5 percent of styrene were investigated as to the rates of their thermal degradation. The rates for polybutadiene indicated an activation energy of 60 kilocalories per mole. The copolymer had very high initial rates of degradation, followed by a rapid drop, so that it was not possible to obtain a reliable activation energy.

Polyacrylonitrile and a copolymer consisting of 31 percent of acrylonitrile and 69 percent of butadiene were investigated with regard to the nature and distribution of volatile products, as well as to the rates of their thermal degradation. The rates were very high initially, but dropped rapidly so that it was not possible to determine accurately the activation energy. The acrylonitrile-butadiene copolymer showed a decomposition pattern similar to that of polybutadiene. Here, too, the activation energy could not be deduced accurately from the rate curves. Comparative thermal stability in terms of temperature, at which half of the polymer sample is evaporated in 35 minutes of heating, is as follows: $407^{\circ} \mathrm{C}$ for polybutadiene, $374^{\circ} \mathrm{C}$ for $\mathrm{SBR}, 364^{\circ} \mathrm{C}$ for polystyrene, $360^{\circ} \mathrm{C}$ for $\mathrm{NBR}$, and $316^{\circ} \mathrm{C}$ for polyacrylonitrile.
\end{abstract}

\section{Introduction}

The copolymers, styrene-butadiene (GR-S) and acrylonitrile-butadiene (nitrile rubber), currently designated in the technical literature as SBR and NBR, respectively, represent two of the more important synthetic rubbers. This paper describes the results of an investigation of the relative thermal stability and of the products of degradation obtained when these rubbers are pyrolyzed in a vacuum. A similar description is given of the thermal behavior of polyacrylonitrile and polybutadiene.

Details of the method employed in this investigation have been described previously $[1-5] .{ }^{2}$ The method consists of two parts. In the first part, a sample weighing 25 to $50 \mathrm{mg}$ is heated in a vacuum, first for $5 \mathrm{~min}$ during a heating-up period, then for $30 \mathrm{~min}$ at a constant temperature; the residue is weighed, and the volatile products fractionated. The fractions are then weighed and analyzed in the mass spectrometer or tested for average molecular weight by a microcryoscopic method. In the second part, a 4 to $5 \mathrm{mg}$ sample in a platinum crucible suspended from a very sensitive tungsten spring balance [3] is heated in a vacuum, and the rate of loss of weight of the sample is observed at intervals. The activation energy of degradation is calculated from the initial rates by using the Arrhenius equation.

\section{Thermal Degradation of Polybutadiene and SBR}

A study of the relative thermal stability of polybutadiene and the copolymer SBR, and of yields and chemical nature of the products resulting from pyrolysis of these two materials, has been reported previously $[2,4]$. Polybutadiene was found to be

${ }^{1}$ Presented before the $132 \mathrm{~d}$ Meeting of the American Chemical Society, New York, N. Y., September $7-12,1957$.

${ }_{2}^{2}$ Figures in brackets indicate the literature references at the end of this paper. more stable than the copolymer. The ratios of small molecular fragments to large ones were 14:84 for polybutadiene and $12: 88$ for SBR.

In this investigation a study was made of rates of thermal degradation of these two substances by the loss-of-weight method, using a very sensitive tungsten spring balance enclosed in a vacuum [3]. Samples of polybutadiene and of SBR $76.5 \%$ of butadiene and $23.5 \%$ of styrene), weighing about $5 \mathrm{mg}$, were used. The materials were prepared by purifying commercial products using a method which has been described previously [2].

Results of rate studies for polybutadiene are shown in figure 1. About 12 to 16 percent of the samples was vaporized at zero time; this vaporization took place during the approximately 15 min heating-up period. Zero time in these experiments was reckoned from the moment the sample had reached the operat-

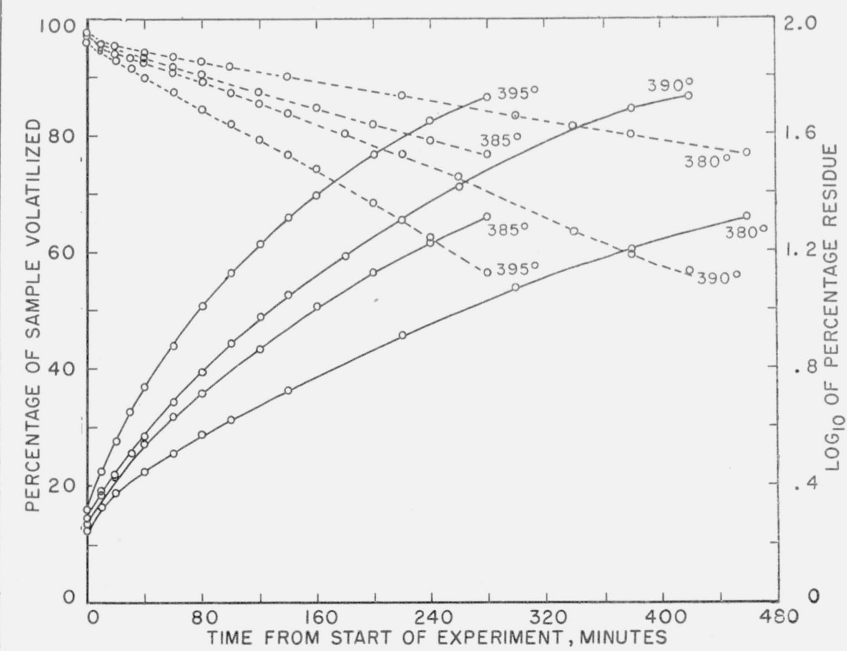

Figure 1. Thermal degradation of polybutadiene.

Solid lines represent percentage volatilization versus time and dashed lines represent logarithm of percentage residue versus time. 
ing temperature. The fact that the logarithm of percentage residue versus time curves deviate only slightly from straight lines indicates that the reaction involved in the thermal degradation of polybutadiene approaches first order.

In figure 2 rate of volatilization is plotted versus amount volatilized. The apparent initial rates are obtained by extrapolating the straight parts of the rate curves to the ordinate. These rates, in percentage of sample per minute, are $0.21,0.31,0.42$, and 0.63 for temperatures $380^{\circ}, 385^{\circ}, 390^{\circ}$, and $395^{\circ} \mathrm{C}$, respectively. On plotting logarithm of the initial rates versus the inverse of absolute temperature, a straight line is obtained, whose slope indicates an activation energy of $62 \mathrm{kcal} / \mathrm{mole}$.

Percentage volatilization of SBR versus time is shown plotted in figure 3 (solid lines). Here again there is considerable loss of weight during the heating up period. Plots of logarithm of percentage residue versus amount volatilized (dashed lines) deviate considerably from straight lines. The reaction involved in the thermal degradation of SBR appears to be more complicated than that for polybutadiene and the reaction is far from first order. Rate of volatilization versus amount volatilized is shown in figure 4. The rates, very high initially, drop rapidly with extent of volatilization. It is not possible to determine with any accuracy the activation energy from these rate curves.

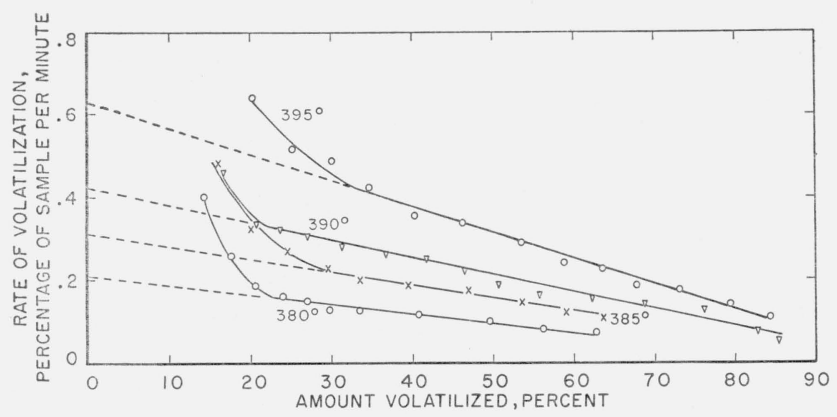

Figure 2. Rates of volatilization of polybutadiene.

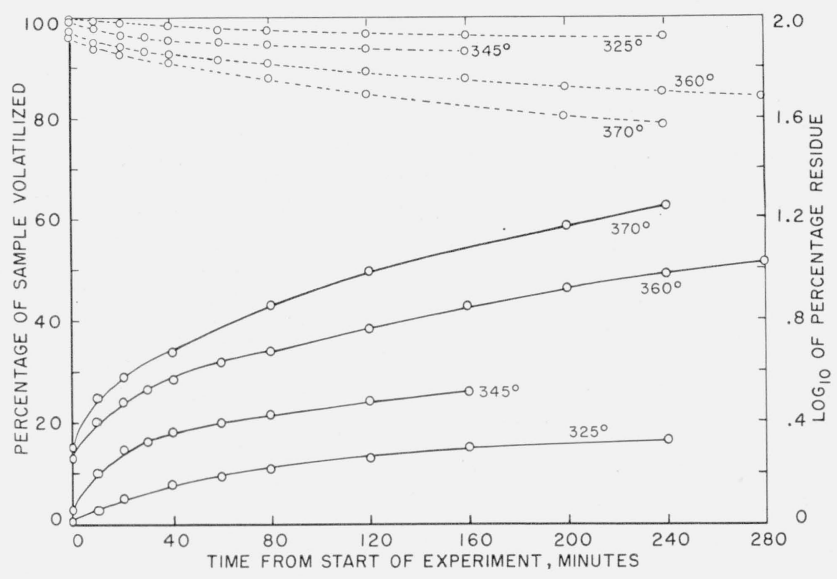

Figure 3. Thermal degradation of SBR.

Solid lines represent percentage volatilization versus time and dashed lines represent logarithm of percentage residue versus time.

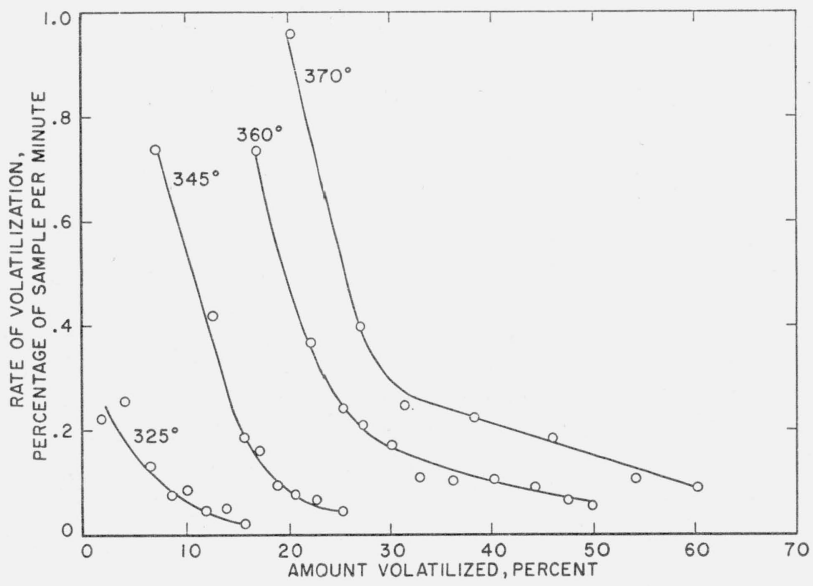

FIGURE 4. Rates of volatilization of SBR.

\section{Thermal Degradation of Polyacrylonitrile and NBR}

The polyacrylonitrile ${ }^{3}$ of high purity and in the form of a fine white powder, had a number-average molecular weight of about 40,000. The NBR rubber was Goodrich Hycar 1042 consisting of about 30 percent of acrylonitrile and 70 percent of butadiene. The rubber was extracted for $24 \mathrm{hr}$ with ethanol-toluene azeotrope in order to remove impurities. It was then kept in a vacuum at 60 to $70^{\circ}$ $\mathrm{C}$ for $5 \mathrm{hr}$. The purified material analyzed 8.2 percent of nitrogen, which corresponds to 31 percent of acrylonitrile. Specimens of polyacrylonitrile and NBR were heated prior to pyrolysis, in a vacuum at $110^{\circ} \mathrm{C}$ to a constant weight.

Results of pyrolysis are shown in table 1. Fraction $\mathrm{V}_{-190}{ }^{4}$ represented less than 0.1 percent of the total volatilized and is not shown in this table. As in the case of many other polymers the ratio $V_{25}: V_{\text {pyr }}$ remained constant throughout the temperature range. On the average, this ratio is $12: 88$ in the case of polyacrylonitrile, and 14:86 in the case of NBR. In the latter case, in calculating the average ratio, results of experiment 1 were excluded, because volatilization was only 9 percent.

As seen from table 1, volatilization of polyacrylonitrile stabilizes at about 70 to 73 percent. This is in agreement with the work of Kern and Fernow [6], who found that dry distillation of this material was accompanied by carbonization of the residue. A possible explanation of this stabilization, as given by McCartney [7] and Houtz [8], is the formation, along the chain, of ring structures involving nitrogen from the CN groups. NBR, which contains only 31 percent of acrylonitrile, does not show any stabilization through the entire temperature range.

Fractions $V_{\text {pyr }}$ from polyacrylonitrile and NBR had a tan waxlike appearance. They were not readily soluble in ordinary organic solvents, including

${ }^{3}$ The authors are indebted to C. A. Sperati of the Polychemicals Department, E. I. duPont de Nemours \& Co., for supplying them with this polymer, which is used in the production of orlon fiber.

${ }_{4}^{4}$ For definition of fractions see footnote to table 1. 
TABLe 1. Pyrolysis of polyacrylonitrile and NBR

\begin{tabular}{|c|c|c|c|c|}
\hline \multirow[t]{2}{*}{ Experiment number } & \multirow{2}{*}{$\begin{array}{c}\text { Tempera- } \\
\text { ture }\end{array}$} & \multirow{2}{*}{$\begin{array}{l}\text { Volatiliza- } \\
\text { tion }\end{array}$} & \multicolumn{2}{|c|}{$\begin{array}{l}\text { Volatile fractions a } \\
\text { based on total vola- } \\
\text { tilized }\end{array}$} \\
\hline & & & $\mathrm{V}_{\mathrm{pyr}}$ & $\mathrm{V}_{25}$ \\
\hline \multicolumn{5}{|c|}{ POLYACRYLONITRILE } \\
\hline $\begin{array}{l}11 \\
2 \\
3 \\
4 \\
5 \\
6 \\
6 \\
8 \\
9 \\
10 \\
11 \\
11 \\
11\end{array}$ & $\begin{array}{l}{ }^{\circ} \mathrm{C} \\
250 \\
250 \\
250 \\
275 \\
300 \\
325 \\
325 \\
325 \\
325 \\
350 \\
350 \\
400 \\
425 \\
455\end{array}$ & $\begin{array}{c}\% \\
21.5 \\
20.7 \\
18.0 \\
34.9 \\
46.6 \\
53.4 \\
52.3 \\
49.7 \\
50.6 \\
57.7 \\
57.9 \\
67.7 \\
70.2 \\
72.8\end{array}$ & $\begin{array}{c}\% \\
86.3 \\
89.1 \\
89.0 \\
88.0 \\
86.3 \\
88.4 \\
88.6 \\
87.4 \\
88.8 \\
88.7 \\
87.8 \\
90.1 \\
87.2 \\
88.3\end{array}$ & $\begin{array}{r}\% \\
13.7 \\
10.9 \\
11.0 \\
12.0 \\
13.7 \\
11.6 \\
11.4 \\
12.6 \\
11.2 \\
11.3 \\
12.2 \\
9.9 \\
12.8 \\
11.7\end{array}$ \\
\hline A verage & -........ & - & 88.1 & 11. 9 \\
\hline \multicolumn{5}{|c|}{$\mathrm{NBR}$} \\
\hline $\begin{array}{l}1 \\
2 \\
3 \\
4 \\
5\end{array}$ & $\begin{array}{l}310 \\
350 \\
365 \\
380 \\
400\end{array}$ & $\begin{array}{r}9.1 \\
29.4 \\
64.5 \\
80.0 \\
95.0\end{array}$ & $\begin{array}{l}74.0 \\
84.5 \\
87.8 \\
84.7 \\
84.8\end{array}$ & $\begin{array}{l}26.0 \\
15.5 \\
12.2 \\
15.3 \\
15.2\end{array}$ \\
\hline Avg (2 to 5 incl. $)$ & --_-..-. & -n.... & 85.5 & 14.5 \\
\hline
\end{tabular}

a The following volatile fractions were collected: $V_{\text {pyr }}$, volatile at the temperature of pyrolysis, but not at $25^{\circ} \mathrm{C} ; \mathrm{V}_{25}$, volatile at $25^{\circ} \mathrm{C}$, but not at $-190^{\circ}$. In the case of other polymers it was usually found necessary to separate this fraction into two parts to facilitate mass spectromete

pyridine. Average molecular weight by the microcryoscopic method in diphenylamine was $330 \pm 9$ for polyacrylonitrile and $401 \pm 3$ for NBR.

Fraction $V_{-190}$ from pyrolysis of polyacrylonitrile was analyzed in the mass spectrometer. This fraction consisted of hydrogen. The $V_{-190}$ fraction from NBR was too small for analysis.

Fraction $V_{25}$ from pyrolysis of polyacrylonitrile when îrst collected was a milky-white liquid. The color of the liquid changed after standing, first to tan and then to brown. Results of mass spectrometer analysis of this fraction are shown in table 2. $V_{25}$ fractions that collected in experiments 1,4 , $5,11,13$, and 14 were analyzed within 1 to 2 hours after they were collected. The time interval between collection and analysis was 1 day for experiments 2 and 7 , and 1 week for experiments 3 and 8 .
The main constituents in $\mathrm{V}_{25}$ are $\mathrm{HCN}$, acrylonitrile, and vinylacetonitrile. The composition of $\mathrm{V}_{25}$ seems to depend on the time interval elapsing between pyrolysis and analysis. This suggests the possibility that some of the components, particularly HCN and acrylonitrile, react and become nonvolatile on standing and, as a result, the remaining volatile constituents become accentuated in the analysis. This could explain why Houtz [8] reported that pyrolysis at $400^{\circ} \mathrm{C}$ yielded only a trace of HCN. On the other hand, Hideo Nagao and coworkers [9] reported the evolution of a considerable amount of HCN when polyacrylonitrile was heated at temperatures from $200^{\circ}$ to $350^{\circ} \mathrm{C}$ in an atmosphere of air or nitrogen. Burlant and Parsons [10] found ammonia as one of the decomposition products from pyrolysis of polyacrylonitrile. We could not ind ammonia in the volatiles.

Results of mass spectrometer analysis of $V_{25}$ from NBR are shown in table 3. Two of the analyses were made shortly after the fractions were collected and kept at the temperature of liquid $\mathrm{N}_{2}$, a third one after an interval of 3 days at room temperature, and a fourth one after an interval of 8 days at the same temperature. All the analyses were similar and the average results are shown in table 3 . The results

TABLE 3. Mass-spectrometer analysis of $V_{25}$ from pyrolysis of nitrile rubber

\begin{tabular}{|c|c|}
\hline Formula of component & $\begin{array}{l}\text { A verage of } \\
4 \text { analyses }\end{array}$ \\
\hline $\begin{array}{l}\mathrm{C}_{2} \mathrm{H}_{4} \\
\mathrm{C}_{2} \mathrm{H}_{6} \\
\mathrm{C}_{3} \mathrm{H}_{4} \\
\mathrm{C}_{3} \mathrm{H}_{6} \\
\mathrm{C}_{4} \mathrm{H}_{6} \ldots \ldots\end{array}$ & $\begin{array}{c}\text { Mole } \% \\
9.1 \\
\text { 4. } 7 \\
3.0 \\
2.9 \\
14.1\end{array}$ \\
\hline $\begin{array}{l}\mathrm{C}_{4} \mathrm{H}_{8} \\
\mathrm{C}_{4} \mathrm{H}_{10} \\
\mathrm{C}_{5} \mathrm{H}_{6} \\
\mathrm{C}_{5} \mathrm{H}_{8} \\
\mathrm{C}_{5} \mathrm{H}_{10}\end{array}$ & $\begin{array}{l}8.3 \\
3.3 \\
2.5 \\
9.1 \\
4.8\end{array}$ \\
\hline $\begin{array}{l}\mathrm{C}_{5} \mathrm{H}_{12} \\
\mathrm{C}_{6} \mathrm{H}_{6} \\
\mathrm{C}_{6} \mathrm{H}_{8} \\
\mathrm{C}_{6} \mathrm{H}_{10} \\
\mathrm{C}_{6} \mathrm{H}_{12}\end{array}$ & $\begin{array}{l}1.6 \\
4.3 \\
6.6 \\
5.4 \\
2.7\end{array}$ \\
\hline $\mathrm{C}_{7}$ to $\mathrm{C}_{10}$ inclusive & 17.6 \\
\hline Total. . & 100.0 \\
\hline
\end{tabular}

TABLE 2. Mass-Spectrometer analysis of $V_{25}$ from pyrolysis of polyacrylonitrile

\begin{tabular}{|c|c|c|c|c|c|c|c|c|c|c|}
\hline \multirow{3}{*}{ Component } & \multicolumn{10}{|c|}{ Time interval between end of experiment and analysis } \\
\hline & \multicolumn{6}{|c|}{1 to 2 hours } & \multicolumn{2}{|c|}{1 day } & \multicolumn{2}{|c|}{1 week } \\
\hline & Expt. $1^{\text {a }}$ & Expt. 4 & Expt. 5 & Expt. 11 & Expt. 13 & Expt. 14 & Expt. 2 & Expt. 7 & Expt. 3 & Expt. 8 \\
\hline $\begin{array}{l}\text { Hydrogen cyanide } \\
\text { Acrylonitrile } \\
\text { Vinylacetonitrile... } \\
\text { Pyrrole } \\
\text { Acetonitrile } \\
\text { Butyronitrile.- } \\
\text { Propionitrile_...-. }\end{array}$ & \begin{tabular}{c} 
Mole \% \\
34 \\
36 \\
30 \\
- \\
\hdashline- \\
- \\
-
\end{tabular} & $\begin{array}{c}\text { Mole } \% \\
22 \\
45 \\
30 \\
3 \\
- \\
- \\
-\end{array}$ & $\begin{array}{c}\text { Mole } \% \\
16 \\
49 \\
32 \\
3 \\
- \\
-\end{array}$ & $\begin{array}{c}\text { Mole } \% \\
68 \\
10 \\
13 \\
-3 \\
3 \\
2 \\
4\end{array}$ & $\begin{array}{c}\text { Mole \% } \\
66 \\
7 \\
13 \\
-6 \\
8\end{array}$ & $\begin{array}{c}\text { Mole \% } \\
63 \\
6 \\
12 \\
-10 \\
3 \\
6\end{array}$ & \begin{tabular}{c} 
Mole \% \\
\hdashline-88 \\
12 \\
- \\
-
\end{tabular} & $\begin{array}{c}\text { Mole \% } \\
28 \\
-63 \\
-6 \\
9\end{array}$ & \begin{tabular}{c} 
Mole \% \\
\hdashline 86 \\
14 \\
-8 \\
-
\end{tabular} & $\begin{array}{c}\text { Mole \% } \\
59 \\
22 \\
19\end{array}$ \\
\hline Total & 100 & 100 & 100 & 100 & 100 & 100 & 100 & 100 & 100 & 100 \\
\hline
\end{tabular}

a Experiment numbers are the same as those given in table 1. 
resemble those obtained previously for butadiene and $\mathrm{SBR}$ (formerly GR-S) [2]. It is rather surprising that none of the products characteristic of polyacrylonitrile pyrolysis showed up in these analyses, although two of the analyses were made shortly after the fractions were prepared and were kept in liquid $\mathrm{N}_{2}$ until the time of analysis. It is likely that in the presence of unsaturated fragments resulting from pyrolysis of the butadiene in the copolymer, the hydrogen cyanide, acrylonitrile, and vinylacetonitrile, polymerize more rapidly than in their absence, and therefore do not show up in the analysis of the acrylonitrile-butadiene copolymer.

A comparison of thermal stabilities of the various polymers and copolymers discussed in this paper, and also of polystyrene, is shown in figure 5 . The curves for polyacrylonitrile and NBR are based on data in table 1, and those for polystyrene, SBR, and polybutadiene were taken from figure 1 of reference [4]. The temperature, $\mathrm{T}_{\mathrm{h}}{ }^{\circ} \mathrm{C}$, at which the sample loses half of its weight by vaporization in $35 \mathrm{~min}$, can serve as a basis of comparison of thermal stability of polymers.

Results of rate studies in the tungsten spring balance are shown for polyacrylonitrile in figures 6 and 7. In figure 6 , percentage of volatilization is plotted versus time from start of experiment. At lower tem-

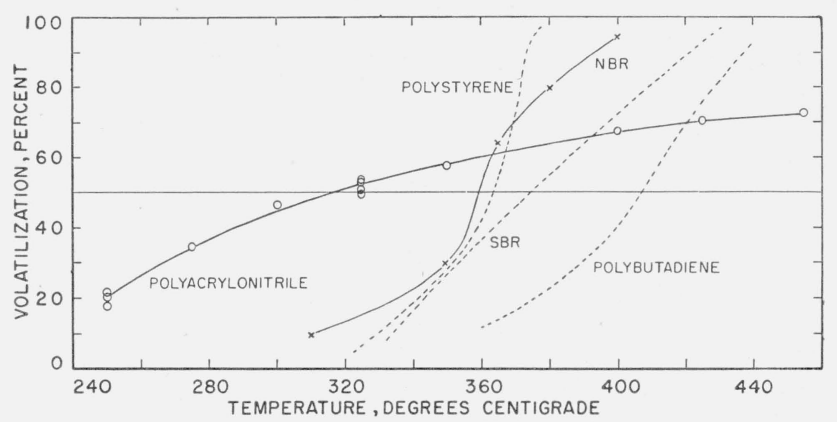

FIGURE 5. Relative thermal stability of polymers and copolymers.

Curves for polystyrene, SBR, and polybutadiene were taken from figure 4 of reference [4]. The $\mathrm{T}_{h}$ values are as follows: $407^{\circ} \mathrm{C}$ for polybutadiene, $374^{\circ} \mathrm{C}$ for SBR, $364^{\circ} \mathrm{C}$ for polystyrene, $360^{\circ} \mathrm{C}$ for $\mathrm{NBR}$, and $316^{\circ} \mathrm{C}$ for polyacrylonitrile.

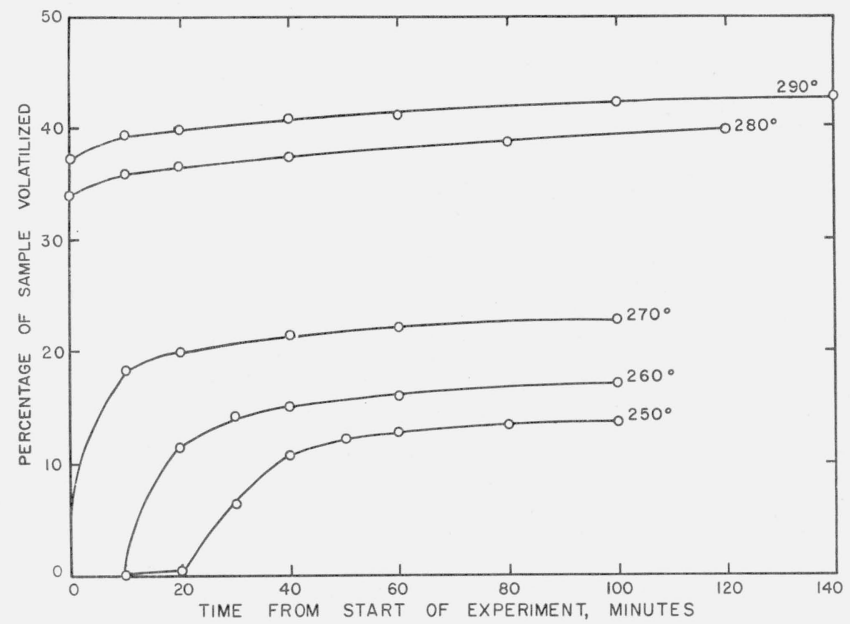

Figure 6. Thermal degradation of polyacrylonitrile.

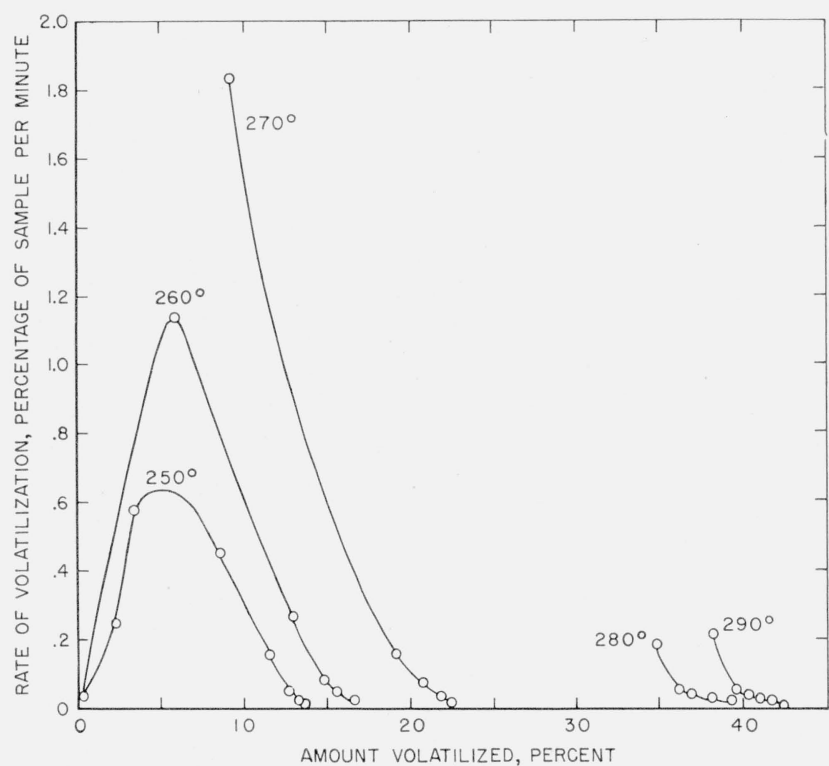

Figure 7. Rates of volatilization of polyacrylonitrile.

peratures, a considerable initiation period is observed. Beyond this period volatilization proceeds rapidly, but soon drops to a very small value, indicating stabilization of the residue. At higher temperatures the initiation period terminates during the 15-min heating-up period and the curves show stabilization of the polymer soon after the sample reaches the operating temperature. These facts can be observed more easily in figure 7 , where rate of volatilization in percent of the original sample per minute is plotted against percentage volatilization. It is not possible to estimate with any degree of accuracy the initial rates or the activation energy based on any of the rates shown in figure 7 .

Results of rate studies for NBR are shown plotted in figure 8 , where percentage volatilization is plotted

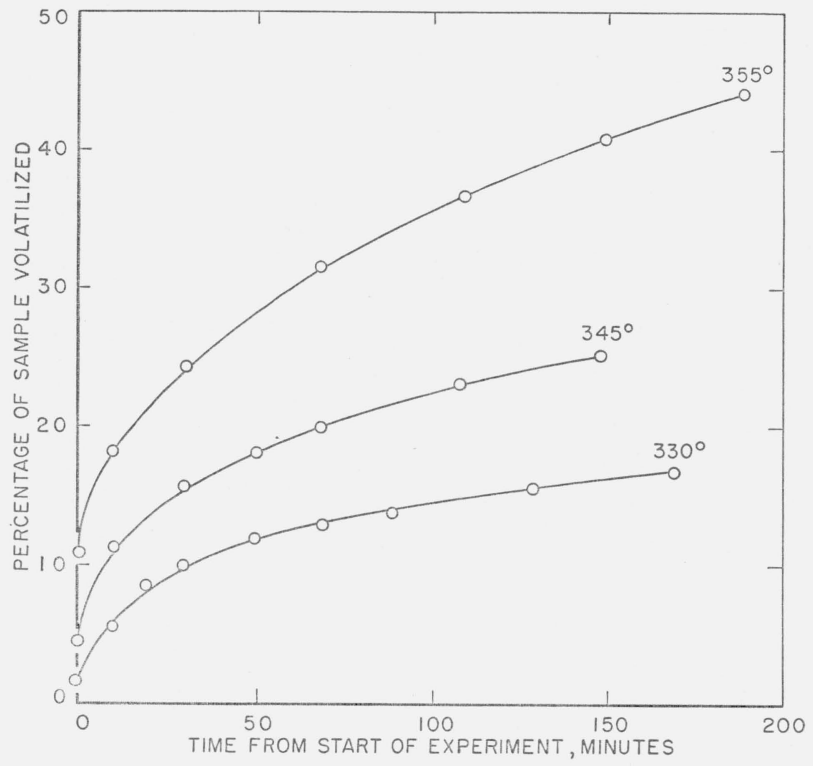

Figure 8. Thermal degradation of NBR. 
versus time from start of experiment, and in figure 9, where rate of volatilization in percent of original sample per minute is plotted versus percentage volatilization. The two sets of curves resemble closely those for SBR shown above (figs. 3 and 4), and no definite conclusion as to initial rates and activation energy can be based on these curves.

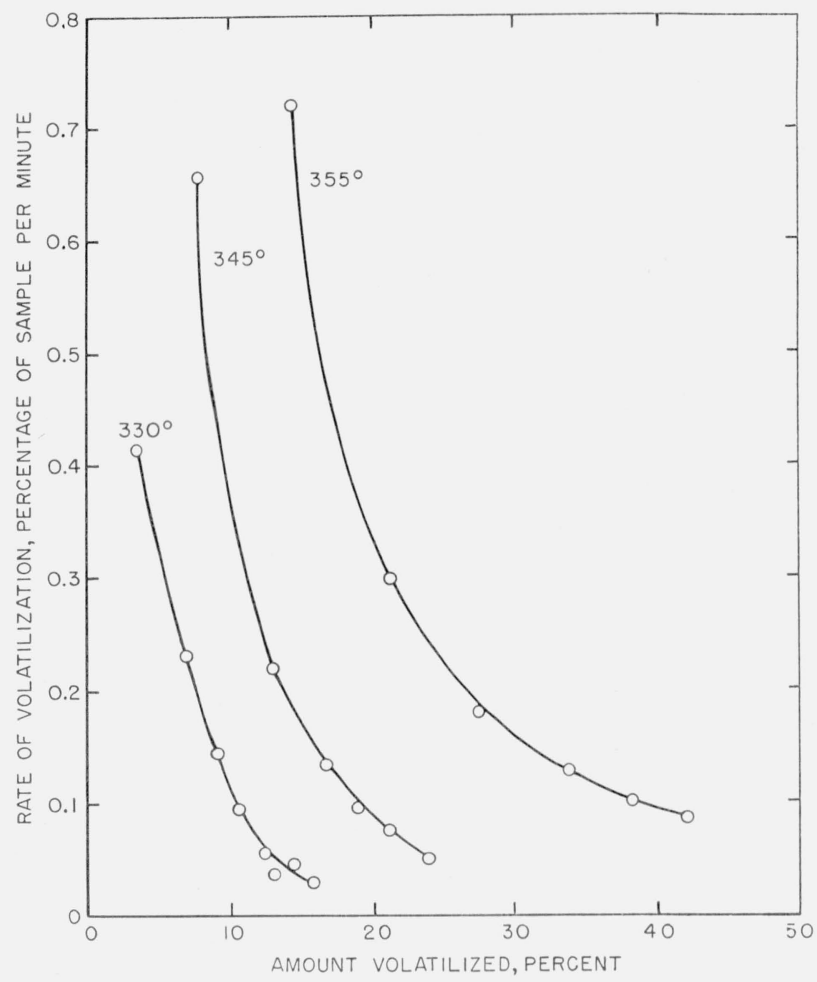

FIGURE 9. Rates of volatilization of NBR.

\section{Discussion}

The main constituents of the light volatile fraction $\mathrm{V}_{25}$ obtained in the pyrolysis of polyacrylonitrile, are hydrogen cyanide, acrylonitrile, and vinylacetonitrile. The hydrogen cyanide most likely forms by splitting-off the chain in the same manner as $\mathrm{CH}_{3} \mathrm{COOH}$ in the pyrolysis of polyvinyl acetate [11], $\mathrm{HCl}$ in the pyrolysis of polyvinyl chloride [12], and $\mathrm{HF}$ in the pyrolysis of hydrofluoroethylene polymers [13].

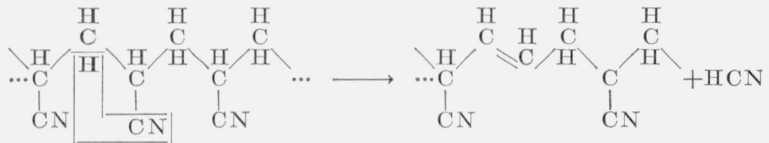

Formation of monomer can be visualized as follows. A random scission of a $\mathrm{C}-\mathrm{C}$ bond in the chain results in two free radical ends.

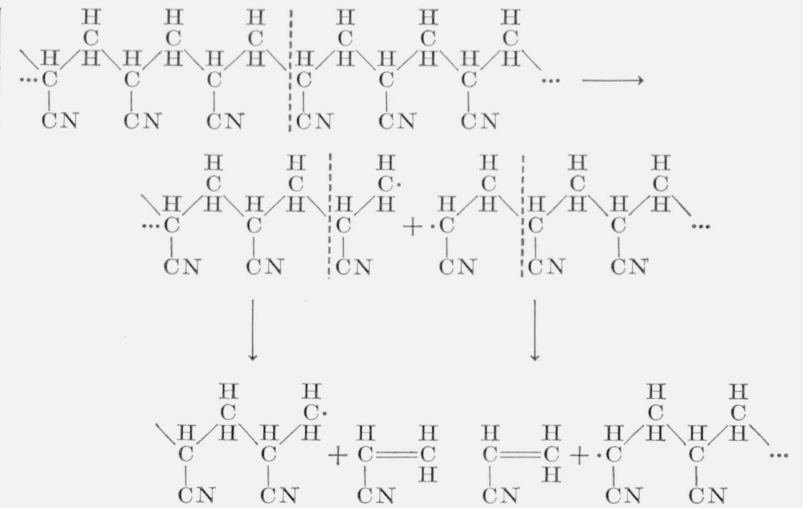

This is followed by an unzipping reaction yielding monomers, as shown in eq (2).

Formation of vinylacetonitrile could be explained if we assume a head-to-head arrangement at some positions in the chain, as shown in eq (3).

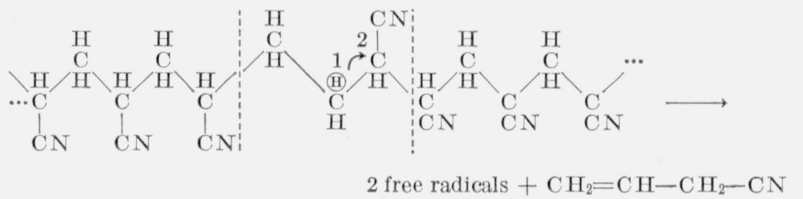

This formation involves $2 \mathrm{C}-\mathrm{C}$ scissions in the chain, followed by a hydrogen transfer from position 1 to position 2.

The pyrolysis curves for polyacrylonitrile (fig. 5) as well as the rate curves (figs. 6 and 7 ) show stabilization during pyrolysis. This is characteristic of polymers in which the loss of side groups from adjacent carbons of the chain results in conjugated double bonds in the chain, since these double bonds tend to enhance the thermal stability of the chain. Polyvinyl chloride [12] and polyvinylidene fluoride [13] may be cited as examples of a behavior similar to that of polyacrylonitrile.

\section{References}

[1] S. L. Madorsky and S. Straus, J. Research NBS 40, 417 (1948) RP1886.

[2] S. L. Madorsky, S. Straus, D. Thompson, and L. Williamson, J. Research NBS 42, 499 (1949) RP1989.

[3] S. L. Madorsky, J. Polymer Sci. 9, 133 (1952); 11, 491 (1953).

[4] S. Straus and S. L. Madorsky, J. Research NBS 50, 165 (1953) RP2405.

[5] S. Straus and S. L. Madorsky, Ind. Eng. Chem. 48, 1212 (1956)

[6] W. Kern and H. Fernow, J. prakt. Chem. 160, 281 (1942); Rubber Chem. and Technol. 1\%, 356 (1944).

[7] J. MeCartney, Polymer degradation mechanisms, NBS Circ. 525, 123 (1950).

[8] R. Houtz, Textile Research J. 20, 786 (1950).

[9] Hideo Nagao, Moriya Uchida, and Teruo Yamaguchi, Kôgyô Kagaku Zasshi 59, 698 (1958).

[10] W. J. Burlant and J. L. Parsons, J. Polymer Sci. 22, 249 (1956).

[11] N. Grassie, Trans. Faraday Soc. 48, 379 (1952); 49, 835 (1953).

[12] R. R. Stromberg, S. Straus, and B. G. Achhammer (unpublished paper).

[13] S. L. Madorsky, V. E. Hart, and S. Straus, J. Research NBS 51, 327 '(1953) RP2461.

Washington, March 5, 1958. 